\title{
Reabilitação de paciente anoftálmico por meio de prótese ocular: relato de caso
}

\author{
Rehabilitation of anophthalmic patient by ocular prosthesis: a case report \\ Rehabilitación del anoftalmo con prótesis de ojo: \\ presentación de un caso
}

Júlia Silva CARVALHO ${ }^{1}$

Cayque Martins da SILVA ${ }^{1}$

Gabriela BENTO ${ }^{2}$

Marcela Filié HADDAD ${ }^{3}$

${ }^{1}$ Graduando(a), Faculdade de Odontologia de Alfenas, Universidade Federal de Alfenas, UNIFAL, 37130.000 Alfenas-MG, Brasil

${ }^{2}$ Cirurgiã-Dentista, Mestranda em Ciências Odontológicas, Universidade Federal de Alfenas, UNIFAL, 37130.000 Alfenas-MG, Brasil

${ }^{3}$ Cirurgiã-Dentista, Mestre e Doutora em Prótese Dentária, Professora da Disciplina de Prótese Parcial Removível, Departamento de Odontologia Restauradora, Faculdade de Odontologia de Alfenas, Universidade Federal de Alfenas, UNIFAL, 37130.000 Alfenas-MG, Brasil

\begin{abstract}
Resumo
Introdução: A perda ocular é muito constrangedora ao seu portador; e a reabilitação por meio de próteses consegue devolver a estética e parte da função perdida. Objetivo: relatar um caso de reabilitação de paciente com anoftalmia unilateral por meio de prótese ocular. Relato de Caso: Foi realizada moldagem da cavidade com hidrocolóide irreversível, o molde foi incluído em mufla e foi prensada a resina acrílica ocular termicamente ativada (RAOTA) previamente selecionada, cor N3. A esclera artificial obtida foi provada no paciente e recebeu os ajustes necessários. Depois, foi realizada a centralização da pupila, foi confeccionado o platô, a íris artificial foi pintada e colada sobre o platô. A superfície da sclera recebeu a caracterização e o conjunto foi recoberto com RAOTA incolor. A prótese ocular recebeu acabamento, polimento e foi instalada. O paciente recebeu instruções de uso e higienização. Foi observado que após a instalação da prótese a estética facial foi restaurada, o suporte palpebral restabelecido, o direcionamento lacrimal foi corrigido e o indivíduo foi reinserido ao convívio social. Conclusão: O tratamento reabilitador atingiu o objetivo de restaurar a estética facial e foi de grande importância para o paciente, pois devolve a autoestima perdida e permitiu que o mesmo retornasse à sociedade.
\end{abstract}

Descritores: Reabilitação; Olho Artificial; Anoftalmia.

\begin{abstract}
Introduction: Eye loss is very embarrassing to its wearer; and rehabilitation through prostheses can restore aesthetics and part of the lost function. Purpose: To report a case of unilateral anophthalmic patient rehabilitation through ocular prosthesis. Clinical report: An impression of the socket was made with irreversible hydrocolloid impression material. Flasking was done and packing was done with the selected heat cure ocular acrylic resin (HCAR) color N3. The obtained artificial sclera was tested in patient and received the necessary adjustments. Then, the centralization of the pupil was performed, plateau was made, artificial iris was painted and glued on the plateau. The sclera surface received characterization and the whole was covered with colorless HCAR. Finally, the ocular prosthesis was finished, polished, and it was installed. The patient was instructed about the use and cleaning. It was observed that after installing the prosthesis facial aesthetic was restored, lid support has been restored and corrected tear direction, in addition to the integration of the individual to social life. Conclusion: The rehabilitation treatment achieved its goal of restoring facial aesthetics and was of great importance for the patient, because it redeemed the lost self-esteem and can return to social life without constraints.
\end{abstract}

Descriptors: Rehabilitation; Eye, Artificial; Anophthalmos.

\section{Resumen}

Introducción: La pérdida ocular es muy embarazosa para su portador; y la rehabilitación a través de prótesis puede devolver la estética y la función perdidas. Objetivo: Presentar un caso de rehabilitación de paciente con anoftalmia unilateral a través de prótesis oculares. Presentación de un caso: La cavidad de moldeo con hidrocoloide irreversible se llevó a cabo, el molde se incluyó en el horno y se presionó resina acrílica para ojo activado térmicamente (RAOAT), N3 color seleccionado previamente. La esclerótica artificial obtenida se ensayó en pacientes y recibió los ajustes necesarios. A continuación, se llevó a cabo la centralización de la pupila, la meseta se hizo, el iris artificial fue pintado y pegado en la meseta. La superficie de la esclerótica recibió caracterización y el conjunto se cubre con RAOAT incoloro. La prótesis ocular fue acabada, pulida y se instaló. El paciente recibió instrucciones de uso y limpieza. Se observó que después de instalar la prótesis estética facial fue restaurada, el soporte de la tapa restaurada, la dirección lágrima se corrigió y el individuo se vuelve a insertar a la vida social. Conclusión: el tratamiento de rehabilitación alcanza el objetivo de restablecer la estética facial y fue de gran importancia para el paciente, devuelve la autoestima perdida y le permitió regresar a la sociedad.

Descriptores: Rehabilitación; Ojo Artificial; Anoftalmos.

\section{INTRODUÇÃO}

A deformidade ocular é sempre problemática para o portador, pois se trata de um defeito na face, região essencial para o relacionamento humano. Esta deformidade ou perda pode ter origem congênita, patológica ou traumática; envolvendo tecidos moles da cavidade ou tecidos ósseos e musculares próximos ${ }^{1}$.
A remoção do globo ocular pode se dar de três maneiras: por evisceração, enucleação ou exenteração. Evisceração é a remoção de conteúdos oculares, preservando as camadas externas do olho; enucleação é a remoção do globo ocular com a preservação dos músculos, pálpebras e glândula lacrimal; e a exenteração é a remoção em bloco 
de toda a órbita ocular, que geralmente envolve a remoção total ou parcial das pálpebras ${ }^{2}$.

Quando não é possível manter o globo ocular, totalmente ou em parte, a reabilitação por meio de prótese ocular é o tratamento de escolha. Esta prótese, apesar de não devolver a função primordial do globo ocular que é a visão, recupera a estética e a autoestima do paciente anoftálmico, mantendo a cavidade anoftálmica preenchida $\mathrm{e}$ possibilitando que o fluído lacrimal seja direcionado e não fique acumulado na cavidade. A prótese possui também a função de prevenir a deformação das pálpebras, proteção da mucosa interna sensível e manutenção do tônus muscular, evitando assim a assimetria facial ${ }^{3}$.

As próteses oculares podem ser classificadas em duas categorias, de acordo com o método utilizado para sua confecção: Próteses Individualizadas: confeccionadas a partir de um molde da cavidade anoftálmica, que dará origem a uma prótese perfeitamente adaptada as estruturas do paciente, restaurando a estética perdida e promovendo movimentação adequada da prótese, conforto e proteção dos tecidos adjacentes; e Próteses Pré-Fabricadas: são próteses de estoque, disponíveis em vários tamanhos e cores, adaptadas à cavidade do paciente. Estas próteses são de rápida aquisição, porém, nem sempre conseguem restabelecer a estética e a movimentação de maneira satisfatória ${ }^{4}$.

Dessa maneira, o objetivo do presente estudo foi relatar um caso clínico de reabilitação de paciente anoftálmico por meio de prótese ocular individualizada.

\section{CASO CLÍNICO}

Inicialmente, o projeto de pesquisa foi submetido à avaliação pelo Comitê de Ética em Pesquisa envolvendo seres humanos da Universidade Federal de Alfenas e obteve parecer favorável (Parecer 1.291.320). Assim, o trabalho consistiu no relato de um caso clínico de reabilitação de paciente anoftálmico unilateral.

O relato de caso a seguir é referente ao paciente E.D., 59 anos de idade, sexo masculino, melanoderma, aposentado, o qual se apresentou a clínica de Odontologia da UNIFAL-MG queixando-se de necessidade protética. Na anamnese, relatou que perdeu o globo ocular esquerdo há cerca de 10 anos, por causa traumática e que, logo após a enucleação, adquiriu uma prótese pré-fabricada, há muitos anos, nos Estados Unidos, onde morava na época, e que agora esta prótese o machucava. Ao exame clínico, foi notado que a prótese era do tipo pré-fabricada, estava menor que sua cavidade ocular e ligeiramente riscada. Desta maneira, optou-se pela confecção de nova prótese.

Inicialmente foram confeccionadas moldeiras em resina acrílica quimicamente ativada (Clássico, Campo Limpo Paulista, SP, Brazil), com dimensões aproximadas às da prótese que o paciente já possuía (Figura 1).

Estas moldeiras receberam acabamento e foram provadas na cavidade do paciente, sendo selecionada aquela que promovia melhor afastamento palpebral, o que facilitaria a moldagem. Em seguida, foi realizada perfuração central nesta moldeira a fim de se promover a adaptação da mesma a uma seringa descartável, e diversas perfurações menores para favorecer a retenção do material de moldagem à moldeira.

A partir daí, teve início a moldagem da cavidade. O material escolhido foi o alginato (Zhermak, Badia Polesine, $\mathrm{RO}$, Italy), que foi proporcionado, manipulado e inserido em uma seringa descartável já com a moldeira acoplada em sua extremidade. Esta moldeira foi posicionada entre as pálpebras do paciente e o alginato foi injetado lentamente. Durante este procedimento, foi solicitado ao paciente que realizasse movimentos com a musculatura orbicular para a obtenção de uma cópia fiel de todos os detalhes da cavidade (Figura 2).

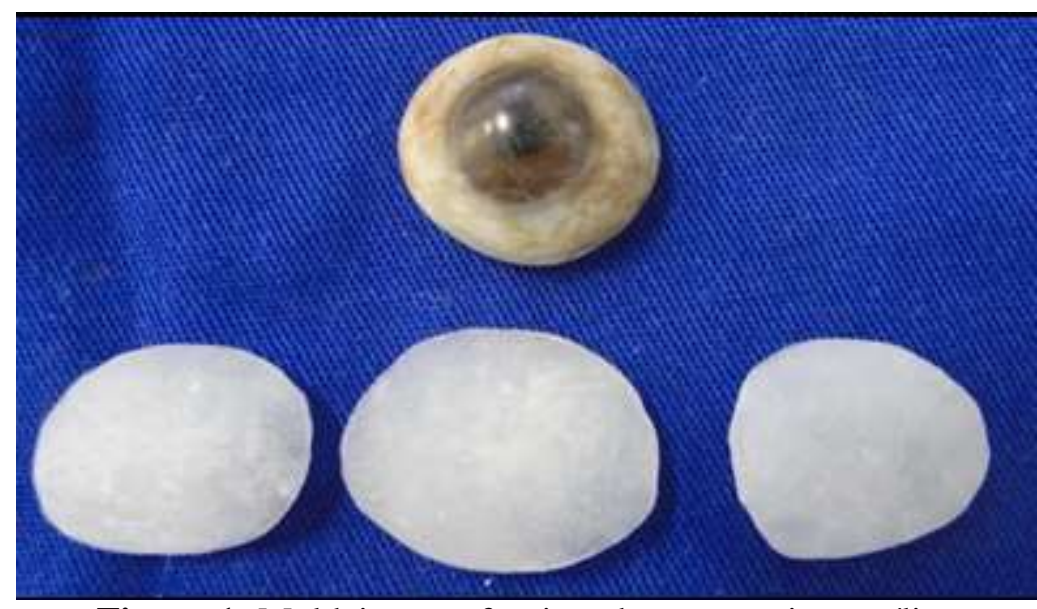

Figura 1: Moldeiras confeccionadas com resina acrílica quimicamente ativada.

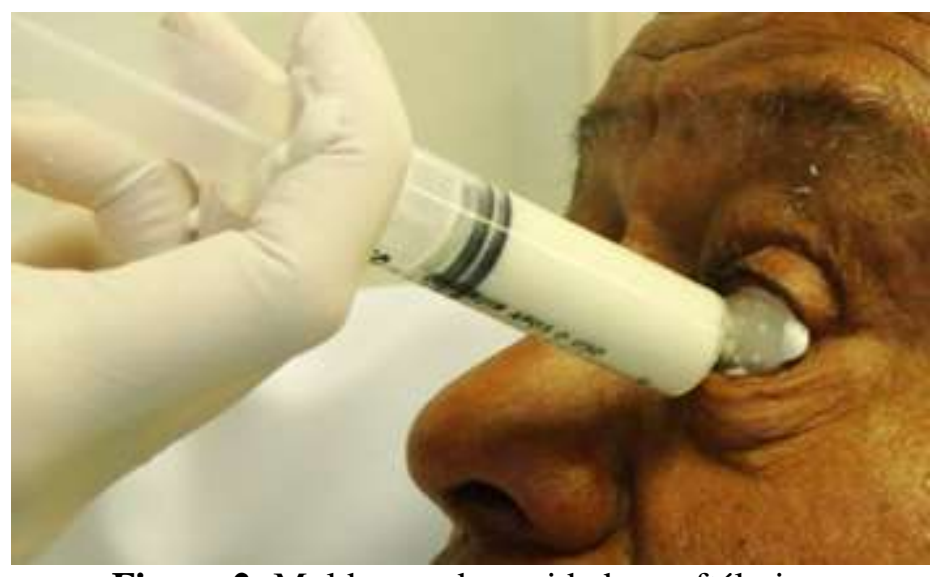

Figura 2: Moldagem da cavidade anoftálmica.

Foi aguardada a geleificação do material, e então o molde foi removido do interior da cavidade do paciente e avaliado quanto sua qualidade. Em seguida, foi manipulado a silicona de condensação de consistência densa (Zhermak, Badia Polesine, RO, Italy) de acordo com as instruções do fabricante, e o mesmo foi utilizado para recobrir uma das faces do molde obtido. Após a polimerização da silicona, o conjunto molde-moldeira foi incluído em mufla preenchida com gesso comum (Figura 3-A). Após a cristalização do gesso, a outra face do molde foi recoberta com silicona, como descrito previamente (Figura 3-B). Após a polimerização do material, a superfície do gesso exposta foi vaselinada, a contra-mufla posicionada, preenchida com gesso e levada para uma prensa de bancada. Após a cristalização do gesso, a mufla foi removida da prensa, aberta e o conjunto molde-moldeira foi removido, criando, assim, um molde para prensagem da Resina Acrílica Ocular Termicamente Ativada (Figura 3-C).

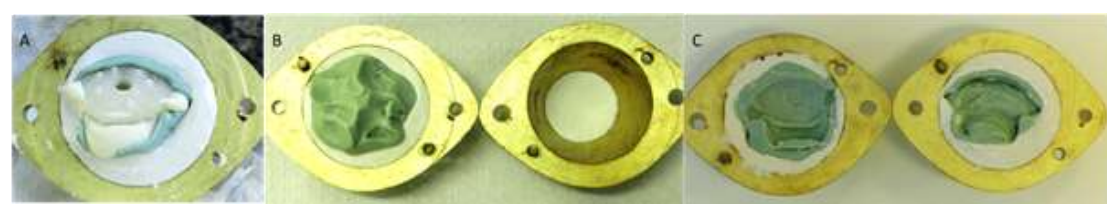

FIGURA 3: A- Inclusão do conjunto molde-moldeira revestido por silicone em mufla. B- Recobrimento do conjunto com silicone para preenchimento da segunda parte da mufla. C- Mufla aberta após a remoção do conjunto, mostrando o molde para prensagem da resina ocular

A etapa seguinte consistiu na obtenção da esclera artificial. Para isso, a RAOTA da cor N3 (Clássico, Campo Limpo Paulista, SP, Brazil) foi manipulada, inserida no molde de silicone dentro da mufla e polimerizada seguindo as instruções do fabricante. Após o resfriamento da mufla, a mesma foi aberta, a esclera artificial removida, realizado o 
processo de acabamento com maxicut e polimento com escova e pedra pomes seguido por e disco de feltro e branco de Espanha. Em seguida, a esclera já polida foi mergulhada em água por 24 horas para eliminação de monômero residual.

Na sessão seguinte, a esclera foi provada na cavidade do paciente. Durante esta etapa, foi avaliado o preenchimento da cavidade, o contorno da pálpebra, a movimentação da esclera e o selamento palpebral. Feitos todos os ajustes necessários, a pupila foi centralizada, realizado platô e a redução da curvatura anterior superficial da esclera em $1 \mathrm{~mm}$. A íris artificial foi pintada sobre papel cartão preto usando tinta a óleo misturada a secante de cobalto (Gato Preto, Sorocaba, SP, Brazil).

Em seguida, foi realizada a caracterização da esclera através da adição de pigmentos e fios do kit de caracterização Peter Thomas. Para isso, o olho sadio do paciente foi observado e foram reproduzidas as manchas e vasos no olho artificial. Foi aguardada a secagem dos pigmentos e a íris artificial foi, então, colada sobre o platô com cola branca escolar (Figura 4).

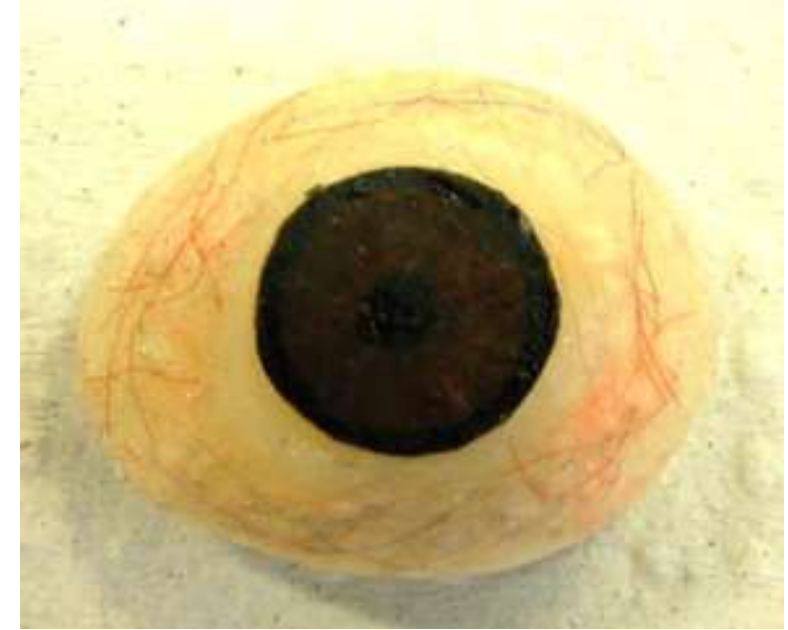

Figura 4: Esclera caracterizada e íris artificial colada sobre o platô.

Decorrida a fase de pintura, uma pequena porção de RAOTA incolor (Clássico, Campo Limpo Paulista, SP, Brazil) foi manipulada e inserida na mufla do lado correspondente ao que, então recobriria a pintura e a caracterização realizadas previamente sobre a esclera (Figura 5). A esclera caracterizada foi posicionada sobre esta resina, a mufla foi fechada, posicionada em prensa de bancada com pressão de 1,25 toneladas por 10 minutos, os excessos de resina foram recortados e a mufla foi transferida para uma prensa de mão, a fim de se realizar a polimerização térmica da RAOTA incolor.

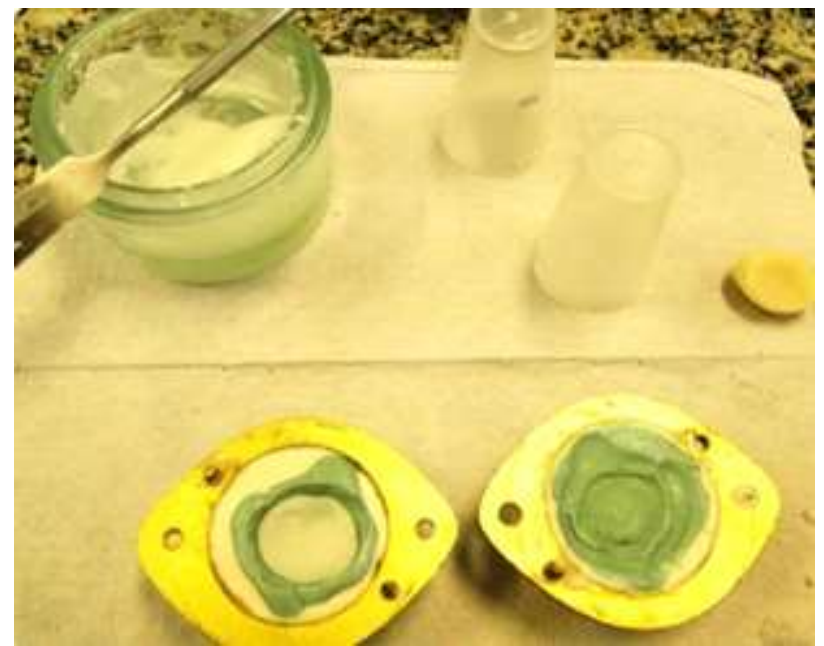

Figura 5: RAOTA incolor posicionada no interior da mufla.

A RAOTA incolor foi polimerizada seguindo as orientações do fabricante. Após o resfriamento, a mufla foi aberta, a prótese ocular removida e submetida a acabamento e polimento da mesma maneira já mencionada após a obtenção da esclera artificial.
A nova prótese foi instalada (Figura 6) e o paciente foi instruído quanto ao uso e higienização da prótese, além de ter sido alertado a respeito da necessidade de polimentos periódicos para correção de possíveis riscos advindo do processo de higienização e/ou quedas da prótese. No momento da instalação, o paciente demostrou muita satisfação com o tratamento realizado, relatando que a prótese estava confortável e esteticamente agradável.

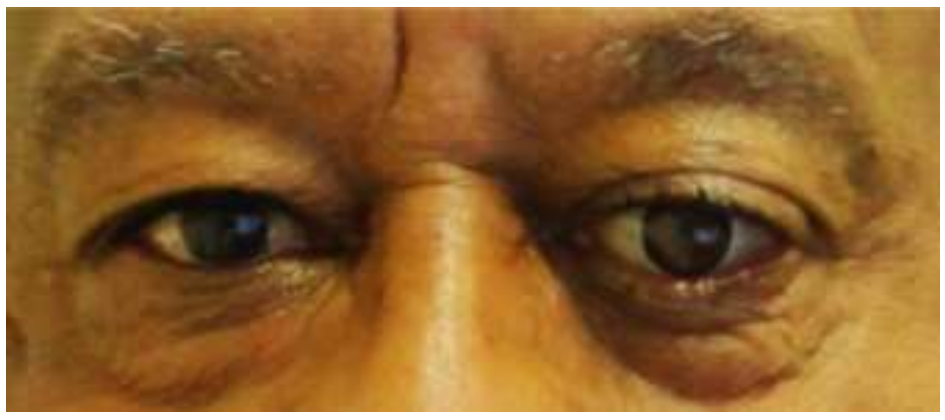

Figura 6: Nova prótese instalada.

\section{DISCUSSÃO}

Para reabilitação do paciente anoftálmico diferentes tipos de próteses são propostas, sendo que a opção por cada uma delas dependerá das características da cavidade, presença ou não de remanescente do globo e relação com a etapa cirúrgica ${ }^{5}$.

As próteses oculares são classificadas como: Cirúrgicas - aquelas que são fabricadas antes da cirurgia para a manutenção do remanescente, não apresentando íris nem esclera; Provisória ou pós-cirúrgica - confeccionadas poucas semanas após a cirurgia, quando a cavidade ainda pode ser modelada; Restauradora - feita após o paciente já ter se adaptado à prótese provisória; Industrializada, de estoque ou pré-fabricada - disponível para compra em ópticas e confeccionadas em fábricas; e Individualizadas obtidas a partir de moldagem da cavidade anoftálmica e confeccionadas de acordo com características individuais do paciente ${ }^{6}$.

Próteses pré-fabricadas podem apresentar três formatos geométricos (oval, standard ou triangular) e três tamanhos diferentes (pequena, média ou grande). Estas são as preferidas pelos pacientes porque podem ser adquiridas facilmente, porém, como não são individualizadas, apresentam mobilidade limitada e podem promover alterações na cavidade anoftálmica, tais como deformações nas dimensões palpebrais devido à excesso de material ou adaptação inadequada da prótese aos tecidos ${ }^{7}$.

Já as próteses individualizadas são confeccionadas a partir de moldagem da cavidade anoftálmica, permitindo, assim, maior mobilidade e dissimulação. O resultado estético e functional das próteses individualizadas é superior ao das próteses de estoque, sendo a próteses de escolha para reabilitação definitiva ${ }^{6,8}$.

De acordo com as características do caso aqui relatado, foi optado pela execução de uma prótese ocular restauradora e individualizada, já que esta oferece um resultado estético e funcional superior à prótese de estoque. A prótese de estoque é muito procurada pelos pacientes por ser de rápida aquisição, porém não oferece a mesma qualidade da individualizada, a mobilidade é limitada e pode promover alterações prejudiciais a cavidade anoftálmica ${ }^{6,8,9}$.

O primeiro passo para se confeccionar uma prótese individualizada é a cópia do defeito por meio de moldagem da cavidade. Para isso, diferentes tipos de materiais odontológicos podem ser utilizados, tais como: ceras, hidrocolóide irreversível e materiais elastoméricos ${ }^{9}$. No presente caso foi utilizado o hidrocolóide irreversível por 
possuir fácil escoamento, permitindo um preenchimento total da cavidade.

Com relação às técnicas de moldagem, a literatura cita impressão direta, impressão externa, impressão com moldeira de estoque, ou com uma moldeira de estoque modificada, impressão com uma moldeira ocular personalizada, com prótese ocular de estoque, com prótese ocular modificada e confecção de esclera em cera. Algumas técnicas dependem de o paciente já ser usuário de prótese ocular e outras da conformação da cavidade anoftálmica. A eficácia e escolha de cada método dependem da experiência do profissional e dos materiais disponíveis ${ }^{9}$. No presente relato clínico, foi utilizada a técnica descrita por Mathews et al. ${ }^{10}$ Bartlett e Moore ${ }^{11}$ e Maia et al. ${ }^{6}$ na qual a moldagem é realizada através da injeção do material com seringa plástica e com moldeira individual de resina acrílica, perfurada com uma adaptação de um conduto central para acoplar a seringa, confeccionada a partir da prótese ocular do próprio paciente.

A partir da moldagem foi confeccionada a esclera, base da prótese ocular. A resina acrílica é o material de escolha para a sua confecção, devido as suas qualidades como: baixo custo, fácil manuseio, adequados valores de resistência, durabilidade, facilidade de limpeza, retenção mecânica confiável e biocompatibilidade ${ }^{7,9}$.

Para a reprodução da íris, no presente caso, foi observada detalhadamente a íris sã do paciente, sua cor, diâmetro e elementos morfológicos sob luminosidade natural indireta. Em seguida, iniciou-se a pintura com tinta a óleo em disco de papel na cor preto, pela cor predominante da íris, seguida da pupila, halo peripupilar e halo externo preconizando as técnicas descritas por Goiato et al. ${ }^{9}$ e Helland ${ }^{12}$

A respeito da pintura, estudos comprovam que diferentes tintas (tinta-guache, acrílica, a óleo, automotiva e até mesmo vernizes) podem ser utilizadas sobre diferentes superfícies (papel cartão branco e preto, papel Carmem, papel fotográfico, diretamente sobre a esclera, pintura invertida sobre calota incolor) ${ }^{9}$.

Outra possibilidade é a utilização da imagem digital para confecção da íris artificial. A utilização da imagem digitalizada da íris remanescente obtida por fotografia digital e impressa em papel através de impressão com jato de tinta apresentou além de resultados estéticos bastante favoráveis, algumas outras vantagens sobre a pintura tradicional, como: técnica simples, tempo de tratamento menor, além de requerer habilidades artísticas mínimas. Exige, porém a utilização de equipamento especial, além da necessidade de recobrir a imagem com um adesivo importado de difícil obtenção ${ }^{9,13}$.

Finalizada a pintura da íris e a caracterização dos vasos sanguíneos através de fibras de seda vermelha, a esclera deve ser recoberta por uma camada de resina acrílica incolor que pode variar de 1 a 3,5 $\mathrm{mm}$, permitindo, pela sua translucidez, a perfeita visualização da íris artificial ${ }^{9}$. A prótese ocular do caso em questão, recebeu esta cobertura e, por fim, acabamento e polimento adequado. Em seguida a prótese foi inserida observando-se a adaptação, a mobilidade a estabilidade e a estética. $\mathrm{O}$ paciente recebeu instruções de uso e dos cuidados diários de higienização. Foram recomendados retornos periódicos para avaliação e acompanhamento da necessidade de troca da prótese ${ }^{7}$

No presente relato os resultados foram satisfatórios, pois a estética facial do indivíduo foi restaurada, o suporte palpebral foi restabelecido e o direcionamento lacrimal corrigido, além de ter resgatado a autoestima perdida, permitindo ao paciente o seu retorno ao convívio social sem constrangimentos.

\section{CONSIDERAÇÕES FINAIS}

Conclui-se então que a prótese ocular é extremamente importante na reabilitação do indivíduo, e deve ser tratada como tal, isto porque interfere em seu convívio social, influenciando em seu estado psicológico. Conclui-se ainda que o campo da reabilitação protética facial deva ser mais explorado pelas instituições de ensino em Odontologia, aumentando assim a oferta à população considerando sua grande importância no âmbito social.

\section{REFERÊNCIAS}

1. Coas VR, Neves AC, Rode SM. Evaluation of the etiology of ocular globe atrophy or loss. Braz Dent J. 2005; 16(3):243-6.

2. Goiato MC, Mancuso DN, Fernandes AU, Dekon SF. A study on the most frequent causes of ocular losses. International Journal of Dentistry. 2011; 24(3):207-86.

3. Raiazada K, Rani D. Ocular prosthesis. J Br Contact Lens Assoc. 2007; 30(3):152-62.

4. Maghami MH, Sodogar AM, Lashay A, Riazi-Esfahani H, Riazi-Esfahani M. Visual prostheses: The enabling technology to give sight to the blind. J Ophthalmic Vis Res. 2015; 9(4):494-505.

5. Cevik P, Dilber E, Eraslan O. Different techniques in fabrication of ocular prosthesis. J Craniofac Surg. 2012; 23(6):1779-81.

6. Maia FAZ, Dias RB, Rezende JRV. Anophthalmic socket impression techniquesfor ocular prosthesis: A comparative study. Rev Odontol Univ São Paulo. 1997; 11(1):85-90.

7. Emídio TCS, Dutilh JDAM, Moro MC, Dutilh CM. Reabilitação com prótese ocular individualizada em pacientes jovens: relato de casos clínicos. Int J Dent. 2011; 10(3):190-4.

8. Chintal SK, Sajjan CS. Prosthetic management of an ocular defect. Contemp Clin Dent. 2010; 1(3):201-3.

9. Goiato MC, Bannwart LC, Haddad MF, dos Santos DM, Pesqueira AA, Miyahara GI. Fabrication techniques for ocular prostheses--an overview. Orbit. 2014; 33(3):22933.

10. Mathews MF, Smith RM, Sutton AJ, Hudson R. The ocular impression: A review of the literature and presentations of an alternative technique. J Prosthodont. 2000; 9(4):210-6.

11. Bartlett SO, Moore DJ. Ocular prosthesis: A physiologic system. J Prosthet Dent. 1973; 29(4):450-9.

12. Helland M. Fabrication of ocular prostheses. In: Beumer J, Curtis TA, Firtell DN, editors. Maxillofacial rehabilitation: prosthodontic and surgical considerations. St Louis: CV Mosby; 1979. pp. 352-62.

13. Artopoulou II, Montgomery PC, Wesley PJ, Lemon JC. Digital imaging in the fabrication of ocular prostheses. J Prosthet Dent. 2006; 95(4):327-30. 


\section{CONFLITO DE INTERESSES}

Os autores declaram não haver conflitos de interesse.

\section{AUTOR PARA CORRESPONDÊNCIA}

\section{Marcela Filié Haddad}

marcela.haddad@unifal-mg.edu.br

Submetido em 10/02/2017

Aceito em 18/02/2017 